\title{
THE POLLUTION SPECTRUM OF OLD PESTICIDES STORAGES IN MOLDOVA
}

\author{
Duca Gh., Bogdevich O.*, Cadocinicov O., Porubin D. \\ Academy of Science of Moldova, 1 Stefan cel Mare str., Chisinau, Moldova \\ *Email: bogdevicholeg@yahoo.com
}

\begin{abstract}
The old pesticide storages in Moldova showed a large quantity of polluted sites. The inventory of POPs polluted sites showed a huge number of extra high polluted sites (more $50,0 \mathrm{mg} / \mathrm{kg}$ ) which need the first place a remediation or other action to eliminate direct contact with people and animals. The pollution spectrum of POPs is a complex and consists of five groups: DDTs isomers, HCHs isomers, Toxaphene mixture, Chlordane and Heptachlor. The principal groups among these substances are DDTs and HCHs isomers.
\end{abstract}

Keywords: soil pollution, POPs, PAHs, pesticides

\section{Introduction}

The inventory of old pesticide storages in Moldova executed by Ministry of Environment and World Bank showed a large quantity of polluted sites (near 1500) remains after the repacking and evacuation project [1,2]. This work was made first of all for Persistent Organic Pollutants (POPs). More that $15 \%$ sites were determined as extra high polluted territory with the POPs concentration in soil more $50,0 \mathrm{mg} / \mathrm{kg}$. They include some of the world's most harmful chemicals including highly toxic pesticides such as HCH, DDT; industrial chemicals such as PCBs. The management of domestic and hazardous wastes is considered as one of the most urgent environmental problems in Moldova. Old pesticide storages are in different conditions and can be classify as important pollution sources for environment. Other toxic substances were detected also in soils which are in list of monitoring substances of Water Framework Directive: PAHs, trifluralin, triazines and others. They are synthetic chemical substances with high toxic characteristics to wildlife and humans. However the information about the actual status and complete pollution spectrum is not sufficient at present. This investigation is important also for the assessment what remediation technologies can be used for the future soil detoxication.

The aim of the study was an assessment of the pollution spectrum in soil at obsolete pesticide storages. This objective was realized by the determination of different type of pollutant in Gas Chromatographs equipped with $\mu$ ECD and mass selective detectors.

\section{Analytical procedure}

Sampling

Samples will be collected according to the Standard Guide for Composite Sampling and Field Sub-sampling for Environmental Waste Management Activities, EPA's Guidance for Choosing a Sampling Design for Environmental Data Collection, EPA QA/G-5S (USEPA 2000c), and other standardized procedures [3-8].

Extraction and clean up.

The extraction and analytical procedures were made by appropriate normative documents [9-13]. Prior to the extraction, the soil samples $(1 \mathrm{~g})$ were spiked with $1 \mathrm{ml}$ of the solution of two internal standards (PCB29 and DCB) of appropriate concentration in the final solution. Extraction was carried out by Microwave Extraction System in the mixture of hexane-acetone (proportion 1:2, $20 \mathrm{ml}$ ) three times. After cooling down, the extracts were collected in the glass condenser and concentrated in n-hexane to a volume of $1 \mathrm{ml}$. The extracts were cleaned up on adsorption chromatography columns filled up with $1 \mathrm{~g}$ of activated silica gel (activated at a temperature of $135^{\circ} \mathrm{C}$ for 16 hours. The column was conditioned with $5 \mathrm{ml}$ of hexane. Interested substances (PAHs and POPs) were eluted from column with $5 \mathrm{ml}$ of $\mathrm{n}$-hexane, followed by $5 \mathrm{ml}$ of $\mathrm{n}$-hexane/dichloromethane mixture (1:1). Final elutes were evaporated in argon flow to $1 \mathrm{ml}$. Sulfur interference was removed by Cupper powder activated in nitric acid.

Analytical determination.

All reagents (solvents, standard solutions, anhydrous sodium sulfate, and pure gases) were of the pesticide grade purchased from Supelco-Aldrich. Agilent 6890 gas chromatograph equipped with $63 \mathrm{Ni} \mu \mathrm{ECD}$ detector, split-splitless injector, and capillary column HP5 were used for the pesticide analysis. PAHs and trizines analysis were performed on an Agilent 6890 gas chromatograph equipped with Agilent 5973 Mass Spectrometer (CG/MS 6890/5973) based on the 
selected ion monitoring system (SIM) of molecular ion peaks and associated characteristic fragment ion peaks. Method conditions are presented in tables (1-4).

Instrument calibration parameters included calculation of the sensitivity (I-SE) as the slope of calibration curve at P-value $<0,05$, linearity (I-LI) as a correlation coefficient for the calibration regression line and the instrument detection limit (IDL) corresponding to 3SD (standard deviation) of five replication of the lowest standard solution.

Table 1.

Experimental Conditions for pesticide determination in GC 6890

\begin{tabular}{|c|c|}
\hline System elements & Method parameters \\
\hline Injection ports & Split/splitless inlet; injection - Split $5: 1,2 \mu 1$, inlet temperature of $300^{\circ} \mathrm{C}$ \\
\hline Column & HP-5: $30 \mathrm{~m}$ Length, $320 \mu \mathrm{m}$ I.D., 0,25 $\mu \mathrm{m}$ Film, $\max 325^{\circ} \mathrm{C}$ \\
\hline Carrier gas & He, $1,4 \mathrm{ml} \mathrm{min}^{-1}$ or Average Velocity $30 \mathrm{~cm} / \mathrm{sec}$, Constant Flow \\
\hline Oven & $\begin{array}{l}\text { First ramp: } 100^{\circ} \mathrm{C}\left(\text { hold } 1 \mathrm{~min} \text { ) to } 200^{\circ} \mathrm{C} \text { at } 20^{\circ} \mathrm{C} \mathrm{min} \text { mil }^{-1} \text { hold } 2 \mathrm{~min} \text {; }\right. \\
\text { Second ramp: } 200^{\circ} \mathrm{C} \text { to } 280^{\circ} \mathrm{C} \text { at } 10^{\circ} \mathrm{C} / \mathrm{min} \text {, hold time } 2 \mathrm{~min} \text {. }\end{array}$ \\
\hline Detector & 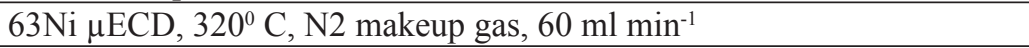 \\
\hline Data collection & ChemStation \\
\hline
\end{tabular}

Table 2.

Experimental Conditions for PAHs and triazines determination in CG/MS 6890/5973

\begin{tabular}{|c|c|}
\hline System elements & Method parameters \\
\hline Injection & Autosampler Agilent $7683 \mathrm{~B}$ \\
\hline Injection ports & $\begin{array}{l}\text { Split/splitless inlet; injection - Splitless (keeping the split closed for } \\
1.0 \mathrm{~min}), 1 \mu \mathrm{l} \text {, inlet temperature of } 300^{\circ} \mathrm{C}\end{array}$ \\
\hline Column & HP-5MS: 30 m Length, $320 \mu \mathrm{m}$ I.D., 0,25 $\mu \mathrm{m}$ Film, $\max 325^{\circ} \mathrm{C}$. \\
\hline Carrier gas & $\mathrm{He}, 1,5 \mathrm{ml} \mathrm{min} \mathrm{m}^{-1}$ or Average Velocity $46 \mathrm{~cm} / \mathrm{sec}$, Constant Flow \\
\hline Oven & $\begin{array}{l}\text { First ramp: } 120^{\circ} \mathrm{C} \text { (hold } 1 \mathrm{~min} \text { ) to } 200^{\circ} \mathrm{C} \text { at } 20^{\circ} \mathrm{C} \mathrm{min}^{-1} \text {; Second ramp: } 220^{\circ} \mathrm{C} \text { (hold } 1 \\
\text { min) to } 290^{\circ} \mathrm{C} \text { at } 5^{\circ} \mathrm{C} / \mathrm{min} \text {, hold time } 2 \mathrm{~min} \text {. }\end{array}$ \\
\hline Detector & Mass detector, EI $70 \mathrm{eV}$, quadropole $150^{\circ} \mathrm{C}$, SIM \\
\hline Data collection & ChemStation \\
\hline
\end{tabular}

\section{Results}

Five POPs compound groups namely $\sum$ DDT, $\sum \mathrm{HCH}$, Chlordane, Heptachlor and Toxaphene have been found in soil samples taken at investigated sites, in concentrations exceeding the national standard for organochlorinated substances in soil $(0.1 \mathrm{mg} / \mathrm{kg})$. Six DDTs isomers, three HCHs isomers, and Toxaphene as a mixture of approximately 200 organic compounds were analyzed in soil and waste samples. The pollution of POPs sites with DDT (88,2\%) and - to lesser extent - with $\mathrm{HCH}(74,9 \%)$ can be defined as widespread. The share of sites contaminated with Chlordane (31\%) and Heptachlor (22,7\%) is also significant. The less number of sites are polluted by Toxaphene mixture (10,2\%), but this pollution is characterized usually by high level. Aldrine, Dieldrine, Endrine, HCB and Mirex were not detected in the investigated samples. The acquired data showed a severe level of soil contamination with DDTs and HCHs at some sites, in the order of hundreds and even thousands of $\mathrm{mg} / \mathrm{kg}$.

Table 3

GC/MS calibration parameters for PAHs and triazines determination

\begin{tabular}{|l|l|c|c|c|c|}
\hline $\mathrm{Nr}$ & Name & Mass ion & \multicolumn{2}{l|}{ ISE } & ILI $\mathrm{ng} / \mathrm{ml}$ \\
\hline \multicolumn{3}{|c|}{ PAHs } \\
\hline 1 & Naphtalene & 128 & 2.71 & 0.999 & 4.0 \\
\hline 2 & Acenaphtylene & 152 & 3.01 & 0.999 & 1.2 \\
\hline 3 & Acenaphtene & 152 & 2.57 & 0.999 & 0.5 \\
\hline 4 & Fluorene & 166 & 2.15 & 0.999 & 0.5 \\
\hline 5 & Phenanthrene & 178 & 3.03 & 0.999 & 0.4 \\
\hline 6 & Antracene & 178 & 3.05 & 0.999 & 1.0 \\
\hline 7 & Fluoranthene & 202 & 3.41 & 0.999 & 2.5 \\
\hline 8 & Pyrene & 202 & 3.49 & 0.999 & 2.1 \\
\hline 9 & Chrysene & 228 & 3.28 & 0.999 & 2.0 \\
\hline 10 & Benz[a]anthracene & 228 & 3.22 & 0.999 & 2.1 \\
\hline 11 & Benzo[b]fluoranthene & 252 & 3.51 & 0.999 & 3.5 \\
\hline 12 & Benzo[k]fluoranthene & 252 & 3.86 & 0.999 & 2.2 \\
\hline 13 & Benz[a]pyrene & 252 & 3.33 & 0.999 & 2.0 \\
\hline
\end{tabular}




\begin{tabular}{|c|c|c|c|c|c|}
\hline 14 & Benz[ghi]perylene & 276 & 3.26 & 0.999 & 2.2 \\
\hline 15 & Dibenz[ah]anthracene & 276 & 4.14 & 0.999 & 2.5 \\
\hline 16 & Indeno[1,2,3-cd]pyrene & 276 & 3.7 & 0.999 & 2.5 \\
\hline \multicolumn{6}{|c|}{ Triazines } \\
\hline 1 & Ametryn & 227 & 3.15 & 0.996 & 3.4 \\
\hline 2 & Atrazine & 215 & 4.15 & 0.998 & 2.5 \\
\hline 3 & Prometon & 225 & 3.25 & 0.995 & 4.1 \\
\hline 4 & Prometryn & 241 & 3.42 & 0.995 & 3.2 \\
\hline 5 & Propazine & 229 & 3.54 & 0.997 & 3.5 \\
\hline 6 & Simazine & 201 & 4.25 & 0.998 & 2.5 \\
\hline 7 & Terbutryn & 241 & 3.64 & 0.996 & 3.8 \\
\hline
\end{tabular}

Table 4

GC calibration parameters for organochlorine pesticides determination

\begin{tabular}{|l|l|c|c|c|c|}
\hline $\mathrm{Nr}$ & Name & Range of standards, $\mu \mathrm{g} / \mathrm{ml}$ & ISE & ILI & IDL ng/ml \\
\hline 1 & Trifluralin & $0.20-2.00$ & 0.40 & 0.999 & 2.0 \\
\hline 2 & a_BHC & $0.05-0.50$ & 2.16 & 0.998 & 1.6 \\
\hline 3 & b_BHC & $0.20-2.00$ & 0.38 & 0.998 & 1.5 \\
\hline 4 & g_HCH & $0.05-0.50$ & 1.76 & 0.998 & 1.2 \\
\hline 5 & Heptachlor & $0.15-1.50$ & 0.36 & 0.995 & 2.5 \\
\hline 6 & Aldrine & $0.10-1.00$ & 2.14 & 0.998 & 1.8 \\
\hline 7 & Chlordane & $0.20-2.00$ & 0.52 & 0.998 & 2.9 \\
\hline 8 & o-p-DDE & $0.20-2.00$ & 1.34 & 0.999 & 3.5 \\
\hline 9 & p,p-DDE & $0.20-2.00$ & 1.38 & 0.998 & 3.6 \\
\hline 10 & Dieldrine & $0.23-2.30$ & 1.68 & 0.998 & 3.2 \\
\hline 11 & o,p-DDD & $0.38-3.80$ & 0.74 & 0.996 & 4.5 \\
\hline 12 & Endrine & $0.40-4.00$ & 1.20 & 0.996 & 4.0 \\
\hline 13 & p,p-DDD & $0.40-4.00$ & 0.67 & 0.996 & 3.5 \\
\hline 14 & o,p-DDT & $0.50-5.00$ & 0.75 & 0.996 & 4.2 \\
\hline 15 & p,p-DDT & $0.40-4.00$ & 1.09 & 0.997 & 4.5 \\
\hline 16 & Mirex & $0.20-2.00$ & 0.91 & 0.999 & 3.5 \\
\hline
\end{tabular}

Some part of site is polluted by several groups of compounds. The toxicology impact on these sites is higher in the case of synergism of different toxicants. The distribution of high polluted sites (more 50,0 mg/kg) by POPs compounds are following: 144 sites are polluted by one substance; 48 sites - by two substances; 9 sites - by three substances, and 3 sites - by four POPs. Actually there are 252 POPs polluted sites with the concentration more that $50.0 \mathrm{mg} / \mathrm{kg}(15,9 \%$ of total 1589 sites).

Sites with high POPs concentration (more $50,0 \mathrm{mg} / \mathrm{kg}$ ) have a additional complex pollution by Trifluraline $(85 \%)$ triazines $(64 \%)$ and PAHs $(33 \%)$. Some sites with relative low POPs pollution have high concentration of these substances. Near $10 \%$ of investigated site have high pollution (more $50,0 \mathrm{mg} / \mathrm{kg}$ ) by other toxic substances which are not included in the inventory program. From other site determined pollutants also have high toxicity and should be monitored.

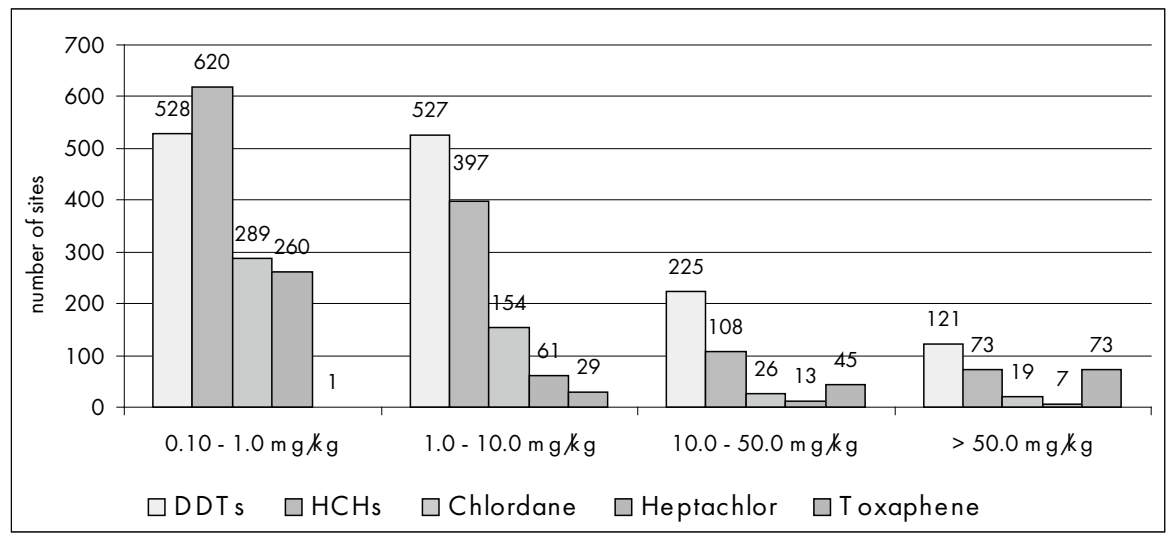

Figure 1. Distribution of POPs polluted sites by pollution clusters 
The interpretation of this large set of analytical results and wide interval of concentration may become easier by showing their distribution (assuming distribution is lognormal) in a few clusters: $0.10-1.0 \mathrm{mg} / \mathrm{kg} ; 1.0-10.0 \mathrm{mg} / \mathrm{kg}$; $10.0-50.0 \mathrm{mg} / \mathrm{kg}$; and $>50.0 \mathrm{mg} / \mathrm{kg}$. The distribution of five investigated groups by pollution clusters gives a better understanding of the extent and severity of contamination (Fig. 1 and 2).

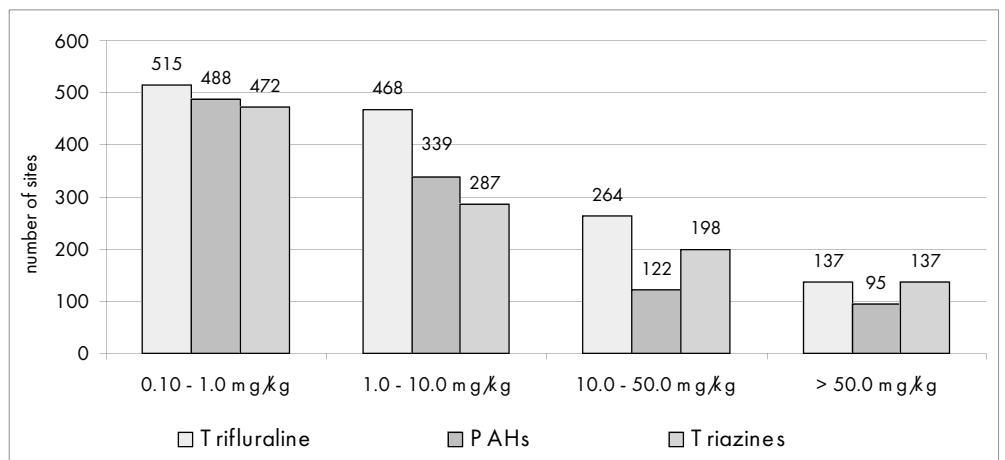

Figure 2. Distribution of polluted sites with other toxic substances by clusters

The spatial distribution of old deposits ranges with the different pollution level in soil is presented on figure 3 . This map is illustrated total POPs concentration in complex soil samples. The density of high polluted sites is higher for raions with more intensive fruit production. 18 raions have more that $15 \%$ of extra high pollution sites (figure 4 ).

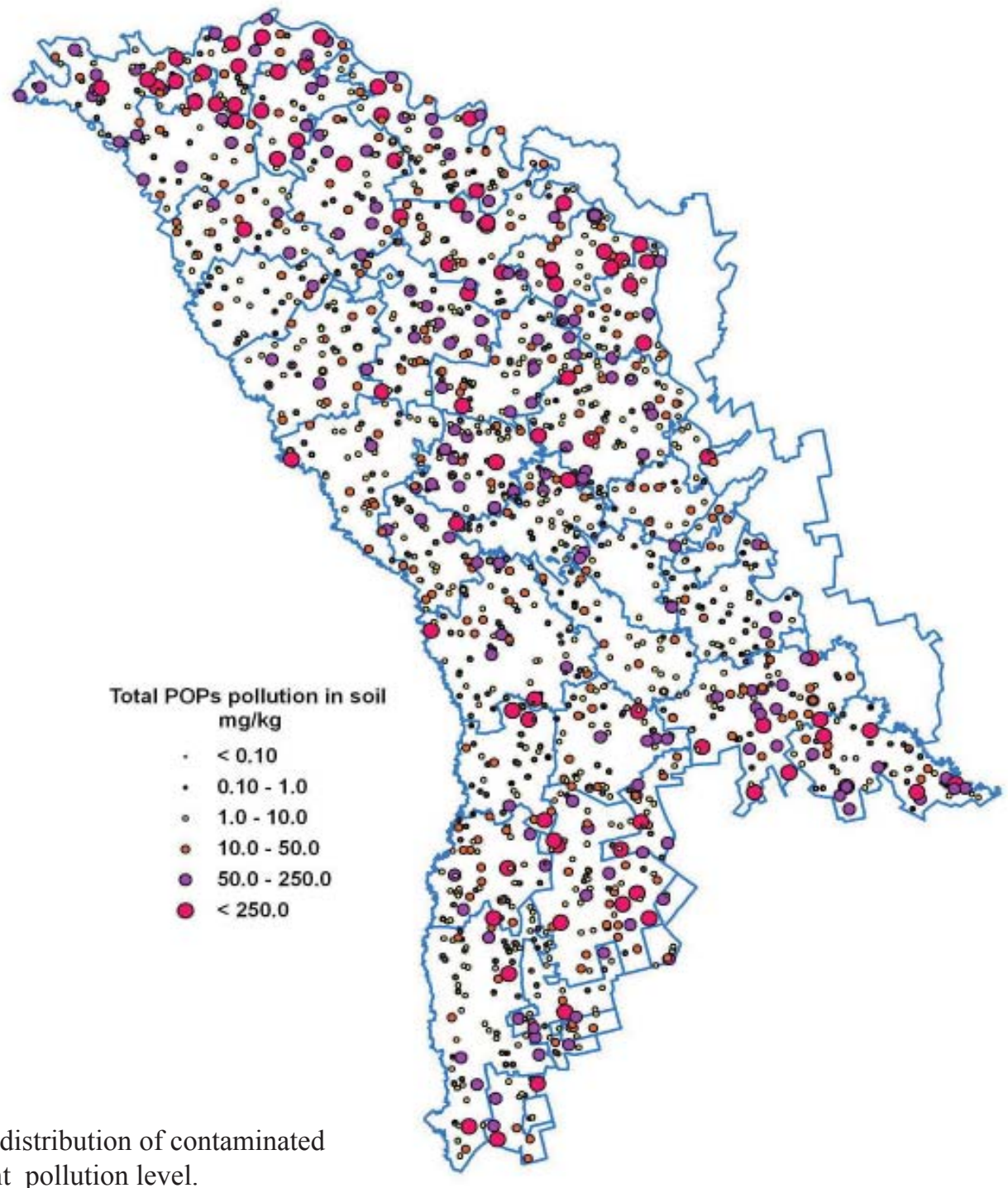

sites with different pollution level. 
The polluted soil with concentration more $50,0 \mathrm{mg} / \mathrm{kg}$ can be classify as hazardous waste. This fact means these sites should to be protected first from the population access and recommended for the remediation to minimize direct contact with animals and people. The sampling of these sites confirmed indirectly a relative big volume of the toxic waste residuals on old pesticide storages

\section{Conclusions}

1. The inventory of POPs polluted sites showed a huge number of extra high polluted sites (more $50,0 \mathrm{mg} / \mathrm{kg}$ ) remained after repacking projects in Moldova which need the first place a remediation or other action to eliminate direct contact with people and animals.

2. The pollution spectrum of POPs is a complex and consists of five groups: DDTs isomers, HCHs isomers, Toxaphene mixture, Chlordane and Heptachlor. The principal groups among these substances are DDTs and HCHs isomers.

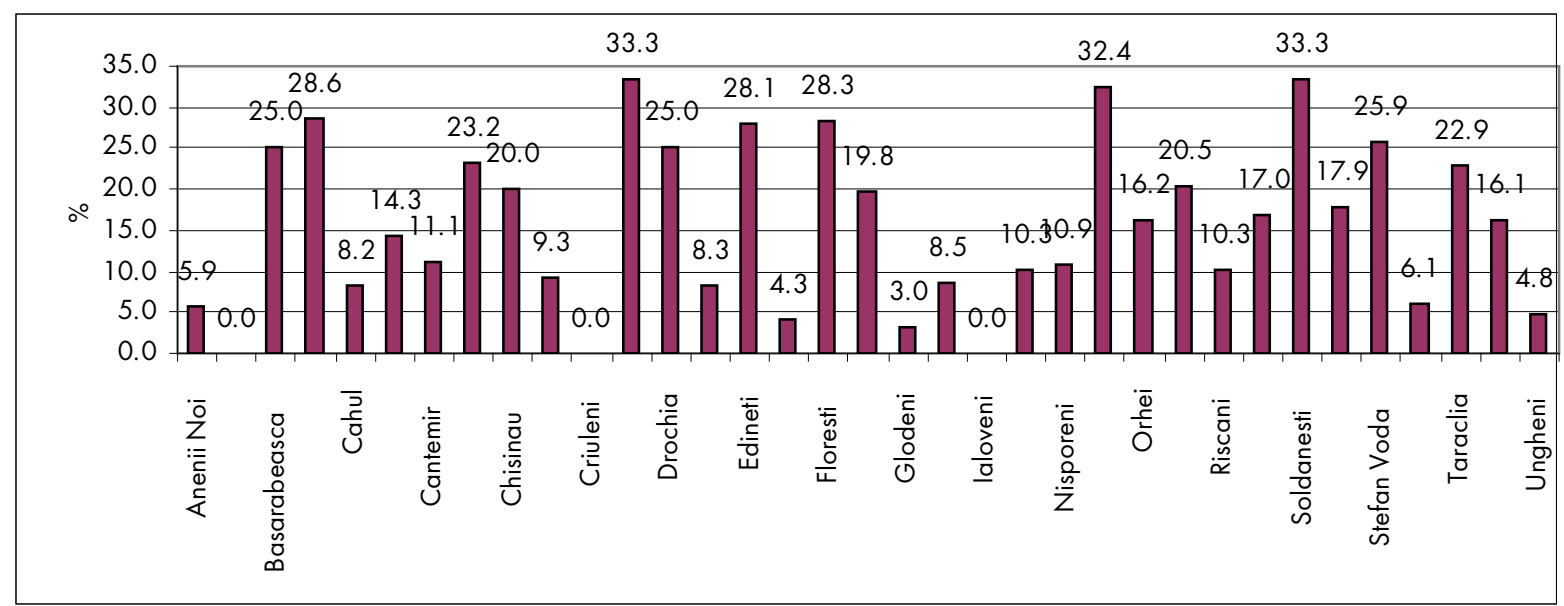

Figure 4. Distribution of high POPs polluted sites $(>50,0 \mathrm{mg} / \mathrm{kg})$ by raions in Moldova.

3. The pollution spectrum is characterized also by other toxic substances as triazines, trifluraline, PAHs and others, which were not analyzed in this study. Determined pollutants are included in normative documents for the monitoring of water quality (Water Framework Directive of EU, etc).

4. The database of POPs polluted sites was created by inventory project in Moldova but this information needs in the development for other pollutants and classification for risk level for environment;

5. The character of pollution spectrum demonstrates a complex character of future remediation and other action by the elimination of negative impact from polluted sites to environmental and public health.

Acknowledgements. The research is made in the frameworks of the project "Creation of the Center for the control and water quality monitoring" of the State Program "Scientific and Management Researches of Water Quality" of the Academy of Sciences of Moldova.

\section{References}

[1]. National Implementation Plan for the Stockholm Convention on Persistent Organic Pollutants (2004) Ministry of Ecology and Natural Resources of the Republic of Moldova, $80 \mathrm{pp}$.

[2]. Environmental Impact Assessment And Environmental Management Plan (2005) Ministry of Ecology and Natural Resources of the Republic of Moldova, GEF PAD Grant for Preparation of Sustainable Persistent Organic Pollutants (POPs) Stockpiles Management Project, 179 pp.

[3]. Assessing Soil Contamination. Reference Manual (2000) FAO. United Nations 232 p.

[4]. Risk Assessment Guidance for Superfund. (2002) EPA/540/1-89/002 December 1989 Vol I, Human Health Evaluation Manual, 17 pp.

[5]. Guidance for Comparing Background and Chemical Concentrations in Soil for CERCLA Sites. (2002) EPA, 540-R-01-003

[6]. RCRA Waste Sampling Draft Technical Guidance Planning, Implementation, and Assessment. (2002) United States, Environmental Protection Agency, Solid Waste and Emergency Response (5305W), EPA530-D-02-002, Office of Solid Waste www.epa.gov/osw 
[7]. Pre-Acquisition Environmental Site Assessment Guidance Manual (1999) National Park Service, Washington, DC 20013

[8]. Environmental Risk Assessment Manual (2008) Scottish Environment Protection Agency Issue 10.1, 94 pp.

[9]. EPA Method 3500B: Organic Extraction and Sample Preparation

[10]. EPA Method 8081A (1996) Organochlorine Pesticides by Gas Chromatography, 44 pp.

[11]. SMV ISO 10382: 2002 Soil quality. Determination of organichlorine pesticides and polychlorinated biphenyls. Gas-chromatographic method with electron captures detection.

[12]. ISO 18287:2006 Soil quality -- Determination of polycyclic aromatic hydrocarbons (PAH). Gas chromatographic method with mass spectrometric detection (GC-MS).

[13]. SM GOST R 51209: 2006 Вода питьевая. Метод определения содержания хлорорганических пестицидов газожидкостной хроматографией. 